\title{
Pretreatment of Aqueous Pectin Solution by Cross-Flow Microfiltration: Study on Fouling Mechanism
}

\author{
Marcelino L. Gimenes, Vitor R. Silva, Fabiane Hamerski, and Agnes P. Scheer
}

\begin{abstract}
This research was carried out to determine the predominant fouling mechanism during the pretreatment of an aqueous pectin solution by cross-flow microfiltration with membrane with nominal size of $0.44 \mu \mathrm{m}$, at different values of transmembrane pressure, temperature, and pectin concentration. To evaluate the predominant resistive mechanism was used series resistance and permeate flux model analysis. The rejection coefficient for pectin varied from 93.4 to $97.9 \%$. The maximum flux observed was $238.69 \pm 6.48 \mathrm{~kg} \mathrm{~m}^{-2} \mathrm{~h}^{-1}$ at transmembrane pressure of $0.12 \mathrm{MPa}$, temperature of $50{ }^{\circ} \mathrm{C}$ and initial pectin of $1.0 \mathrm{~g} \mathrm{~kg}^{-1}$. The dominant restrictive mechanism observed was the cake layer formation, for all assay evaluated.
\end{abstract}

Index Terms —Pectin, microfiltration, permeate flux, fouling.

\section{INTRODUCTION}

Pectin is a family of complex polysaccharides constituted of galacturonic acid units linked by $\alpha(1 \rightarrow 4)$ glycoside bonds It also presents esterified regions with methylic groups and branches constituted of neutral sugars. The structure of the lateral chain and the degree of esterification characterize the capacity of gelling, solubilization, and aggregation of pectin in solutions. Due to its gelling characteristic, pectin is a very important raw material in the jelly, sweet, and preserve industries [1]-[3]. In the production of pectin, the most costly step is the purification process, which requires large amounts of ethanol to precipitate pectin from the extraction solution. The ethanol solution is later evaporated by vacuum [4], [5].

The porous membrane separation process has been widely used in the food industry, especially in the clarification of juices. The traditional macromolecular fractioning processes that are frequently used in the industry can be optimized with the implementation of membrane separation steps [6]-[8]. According with Moresi [9], the implementation of a microfiltration step before the precipitation with ethanol results in the successful concentration of the extraction solution, reducing the volume of ethanol required to precipitate pectin, and consequently, reducing the energy spent in the evaporation step. Cho et al. [10] incorporated a system of cross-flow microfiltration with a $0.2-\mu \mathrm{m}$ cellulose membrane to a purification step in the extraction of pectin. With the microfiltration system, was achieved a reduction of $75 \%$ of the volume of ethanol required.

However, the reduction in the permeate flow is a

Manuscript received September 5, 2013; revised December 10, 2013. This work was supported by CAPES, Brazil.

F. A. Gimenes is with the Chemical Engineering Department, Maringá State University, Maringá, Brazil (e-mail: marcelino@ deq.uem.br).

V. R. Silva, F. Hamerski, and A. P. Scheer are with the Chemical Engineering Department, Federal University of Paraná, Curitiba, Brazil (e-mail: vrenan@ufpr.br, fabianehamerski@ufpr.br, agnesps@ufpr.br). restriction of membrane processes. Pectin is undesirable in the fruit and vegetable juice clarification process, as the typical concentrations of $1 \%$ mass precipitate on the membrane surface as a viscous gel, increasing the resistance to permeation [11]-[13]. The polarization layer is the concentration boundary layer adjacent to the membrane surface, formed in the beginning of process, resulting in a sharp flux decrease, which is stabilized by the renewal surface effect promoted by the crossflow flux [14]. However, a gradual decrease in flux is also observed due to physical and chemical interactions of pectin with the membrane, known as fouling. Fouling limits the flux by continuous blocking of membrane, thus gradually reducing the permeate flux [15].

Fouling is an intrinsic problem associated to all kind of membrane process and the extent to which fouling can be controlled is proportional to the understanding of the mechanisms that govern this process. The identification of these phenomena associated with the operating conditions allows to assessment the technical viability of process. This study evaluated the effect of operational parameters in the permeate flux and fouling resistance and estimated the major blocking mechanism present in the concentration of pectin solutions.

\section{MATERIALS AND MethodS}

\section{A. Experimental Procedure}

This study was performed in a crossflow microfiltration pilot unit used in previous studies [16], [17]. This system was made with stainless steel for use an alumina ceramic membrane (Fairey Ceramics Inc ${ }^{\mathrm{T} W}$, London, England) with a nominal pore size of $0.44 \mu \mathrm{m}$, surface area of $0.06 \mathrm{~m}^{2}$, length of $60 \mathrm{~cm}$ and external diameter of $2.0 \mathrm{~cm}$. The feed flow adopted was $1.0 \mathrm{~m}^{3} \mathrm{~h}^{-1}$ and the temperature of the solution was adjusted through a serpentine immersed in a heating bath (Quimis, model Q215, São Paulo, Brazil). The pectin solutions were prepared by slowly dispersion of commercial pectin (CP Kelco, Limeira, Brazil) in deionized water with mixing (Q-250M at $500 \mathrm{rpm}$, QUIMIS ${ }^{\mathrm{TM}}$ ). The permeate flux was determined by gravimetry by (1).

$$
J_{P}=\frac{m_{P E R}}{t \cdot S}
$$

where $J_{P}$ is the permeate flux $\left(\mathrm{kg} \mathrm{m}^{-2} \mathrm{~h}^{-1}\right), m_{P E R}$ is the permeate mass $(\mathrm{kg}), t$ is the filtration time (h), and $S$ is the membrane surface area $\left(\mathrm{m}^{2}\right)$.

\section{B. Experimental Design}

The experiments were performed with factorial design $2^{3}$ evaluating: temperature $\left(30{ }^{\circ} \mathrm{C}\right.$ and $\left.50{ }^{\circ} \mathrm{C}\right)$, transmembrane 
pressure $(0.04 \mathrm{MPa}$ and $0.12 \mathrm{MPa})$ and initial pectin concentration $(1.0 \mathrm{~g} / \mathrm{L}$ and $2.0 \mathrm{~g} / \mathrm{L})$ with central point $\left(40{ }^{\circ} \mathrm{C}\right.$, $0.08 \mathrm{MPa}$ and $1.5 \mathrm{~g} / \mathrm{L})$. The initial solution quantity used in each experiment was $6 \mathrm{~kg}$ with a fixed time of 1 hour. All experiments were made in triplicate. Analysis of variance was performed for the treatments with Tukey's test to compare means with $5.0 \%$ of significance level.

The system was operated with feed flux of $1.0 \mathrm{~m}^{3} \mathrm{~h}^{-1}$ and mean surface velocity of $3.82 \mathrm{~m} \mathrm{~s}^{-1}$. As a result, the Reynolds number varied between 5,400 and 12,000 for the experiments, ensuring a turbulence condition in all tests.

The cleaning process was made after each replicate of assays, started with the washing with deionized water at boiling point. After the cleaning system, the membrane was removed of the system and immersed in ultrasonic bath (Ultrasonic cleaner USC 1400 - UNIQUE ${ }^{\mathrm{TM}}$ ) with successive cycles of 10 minutes of cleaning with solutions of $\mathrm{NaOH}(1.0 \% \mathrm{~m} / \mathrm{V})$, deionized water and Citric Acid $(0.8 \%)$. All chemical products used were analytical standard.

\section{Sample Analysis}

Dynamic viscosities of the pectin solutions were measured in a capillary viscometer (Schott TM CT 52). Laser granulometry (1064 CILAS liquid) and turbidity (DLM DEL 2000B LAB) analyses were performed to characterize the distribution of pectin aggregates in the dispersed portion of solution.

The pectin concentration was determined by spectrophotometry (Pro-analise series 1000 UV/VIS spectrophotometer, São Paulo, Brazil) at $300 \mathrm{~nm}$ using deionized water as blank [18]. The pectin rejection coefficient was calculated with (2) [19].

$$
C R=\left(1-\frac{C_{P}}{C_{F}}\right) \cdot 100
$$

where $C R$ is the rejection coefficient $(\%), C_{P}$ is the pectin concentration in the permeate flow $\left(\mathrm{g} \mathrm{kg}^{-1}\right)$, and $C_{F}$ is the feed concentration $\left(\mathrm{g} \mathrm{kg}^{-1}\right)$.

\section{Fouling Resistance}

The fouling resistance effects were estimated using the fouling resistance model [19], [20]. This model describes the effects that may interfere with the permeate flux as a function of the total resistance $R_{T}$. The permeate flux can be described as (3):

$$
J_{P}=\frac{\Delta P}{\mu \cdot R_{T}}
$$

where $\Delta P$ is the transmembrane pressure, $\mu$ is the permeate viscosity.

Fouling resistance $R_{F}$ is obtained by difference between the total resistance $R_{T}$ of pectin solution permeation and the hydraulic membrane resistance (4):

$$
R_{F}=R_{T}-R_{M}
$$

The hydraulic resistance membrane $R_{M}$ was measured by (5) with deionized water.

$$
R_{M}=\frac{\Delta P}{\mu_{W} \cdot J_{W}}
$$

where $J_{W}$ ' is the water permeate flux through the cleaning membrane and $\mu_{W}$ is the water viscosity.

\section{E. Mathematical Models of the Permeate Flux}

The pore blocking models depend on the interaction between the membrane and the solute. In this study, the pore blocking models and the classical filtration theory at constant pressure were used. The classical filtration model adopted [12], [13], [20], expressed as permeate flux, follows (6):

$$
\frac{1}{J_{P}(t)}=R_{M E} \cdot \frac{\mu}{\Delta P}+m_{P E R}(t) \cdot \frac{\mu \cdot C_{F} \cdot \alpha}{2 \cdot S \cdot \Delta P}
$$

where $R_{M E}$ represents the total resistance of the membrane, $m_{P E R}(t)$ is the mass of permeate accumulated up to instant $t$ and $\alpha$ is the resistance of the surface cake.

The pore blocking models is an empirical model proposed by Hermia [21], and adapted for cross-flow filtration system [22]-[24]. The general pore blocking model can be described by (7):

$$
\frac{d J_{P}}{d t}=-k_{n} \cdot\left(J_{P}-J^{*}\right) \cdot J_{P}{ }^{2-n}
$$

where $k_{N}$ and $n$ represent the phenomenological coefficient and the general fouling index, respectively, and $J *$ is the ideal critical flux for which fouling does not occur. The integration of (7) gave the distinct pore-blocking mechanisms as a function of the index $n$.

For $n=2.0$, the complete pore blocking model is defined in (8). In this model, the particles are bigger than the pore opening, a part of the membrane surface covered by the particles is sealed, and permeation is prevented by the reduction of the surface area.

$$
J_{p}(t)=J_{L I M}+\left(J_{O}-J_{L I M}\right) \cdot \exp \left[-k_{2.0} \cdot t\right]
$$

where $J p(t)$ is the permeate flux value at time $t, J o$ is the permeate flux value at the initial time and $J_{L I M}$ is the steady-state value of permeate flux.

The value $n=1.5$ gives the internal pore blocking model. This model, (9), considers that the particle size is smaller than the pore opening and that the particles tend to be retained inside the pores due to adsorption on the pore walls or by deposition on the internal cavities. As the blocking occurs internally, the reduction of the pore opening by blocking becomes independent of the flux conditions, that is, the flux decays to a null value.

$$
J_{P}(t)=\frac{J o}{\left[J o+J O^{0.5} \cdot k_{1.5} \cdot t\right]^{2}}
$$

The value $n=1.0$ gives the partial pore blocking model, (10). In this case, the particle size is close to the pore size and they tend to agglutinate in specific regions of the pore, without closing it. 


$$
J_{P}(t)=\frac{J o}{J_{L I M}-J o \cdot\left(\exp \left[k_{1.0} \cdot J_{L I M} \cdot t\right]-1\right)}
$$

For $n=0$, the resulting model corresponds to the cake filtration, (12). Considering the effect of larger particles on the pores and that they agglomerate on the membrane surface forming a filter cake, they constitute an additional resistance to the process.

$$
k_{0} \cdot t=\frac{1}{J_{L I M}^{2}} \cdot \ln \left[\frac{J_{P}(t)}{J o} \cdot \frac{J_{O}-J_{L I M}}{J_{P}(t)-J_{L I M}}-J_{L I M} \cdot\left(\frac{1}{J_{P}(t)}-\frac{1}{J_{O}}\right)\right]
$$

The models were submitted to non-linear regression by optimization by Simplex algorithm. The sum of the squares residues $S S R$ and coefficient of determination $\mathrm{R}^{2}$ were determined as the evaluation criteria of the models.

The mean experimental values were adopted for parameters $J_{L I M}$ and $J o$, adjusting only the $k_{n}$ parameter.

\section{RESULTS AND DISCUSSIONS}

\section{A. Fouling Resistance}

A high retention of pectin was observed in all assays, as showed in Table I. The rejection coefficient was within 93.4 $\pm 0.7 \%$ and $97.8 \pm 0.5 \%$. Much of the pectin in solution was found dispersed in the solution, with average turbidity values between 21.62 and $41.89 \mathrm{NTU}$, and this conditions, pectin take the form of aggregates groups with size between 500 $\mathrm{mm}$ and $0.01 \mu \mathrm{m}$, as Fig. 1, formed from Van der Waals bonds and hydrogen bridges between available hydroxyl. Due these aggregates, the cross-flow microfiltration showed high values of pectin rejection. Lower values were observed at the highest experimental temperature $\left(50{ }^{\circ} \mathrm{C}\right)$, where the solubility of pectin is increased and the solution viscosity is reduced, favoring the mass transfer and the permeation, especially of the neutral sugar and bound residues in pectin.

In previous works [16], [17] the authors observed that the permeate flux has strong dependence of the temperature, pectin concentration and transmembrane pressure. Table I showed the values of the permeate flux at the final of operation and fouling resistance. The hydraulic membrane showed means between $3.49 \pm 0.28$ and $3.91 \pm 0.28$, statistically equal for all assays, what indicated the efficiency of the cleaning procedure proposed.

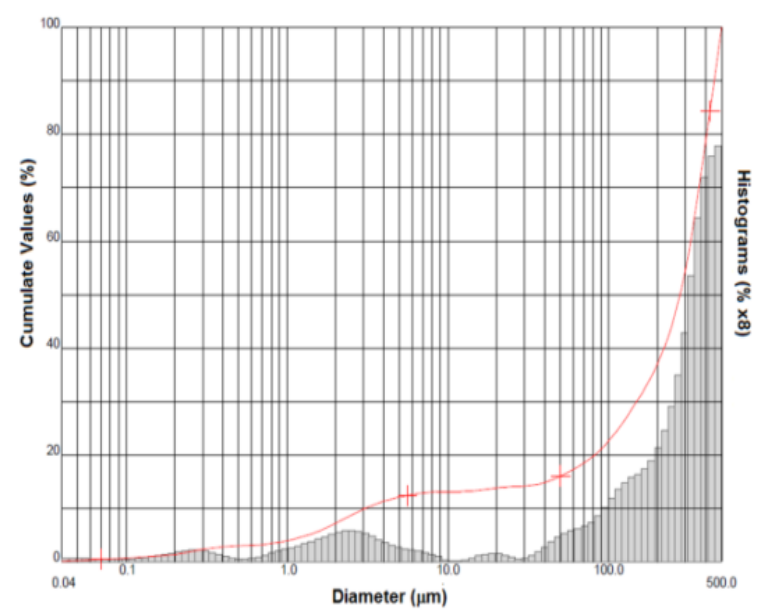

Fig. 1. Granulometric distribution of dispersed pectin.
Temperature is favorable for the viscosity and diffusion coefficient pectin, thus high temperature is favorable for water permeation; while the initial pectin concentration interferes on the resistance mechanisms, particularly with the respect to the polarization layer and gelling surface layer. The transmembrane pressure is the driving force, so its increase is favorable to the permeation until the limit, that the equilibrium between the surface renewal and resistive mechanisms.

This behavior was similar that observed by Wang [20], and can be explained by solubilization of pectin, reducing it to particle aggregates formation and its surface deposition.

TABLE I: ANAlyses OF STEADy-StATE PERMEATE FluX, ReJeCtion COEFFICIENT AND FOULING RESISTANCE

\begin{tabular}{cccc}
\hline \hline Assays* & $\mathrm{CR}(\%)$ & $J p\left(\mathrm{~kg} / \mathrm{m}^{2} \mathrm{~h}\right)$ & $\begin{array}{c}\mathrm{R}_{\mathrm{F}} \times 10^{-8} \\
\left(\mathrm{~m}^{2} / \mathrm{kg}\right)\end{array}$ \\
\hline $0.04 / 30 / 1.0$ & $97.6 \pm 0.2^{\mathrm{AB}}$ & $143.64 \pm 10.06^{\mathrm{cd}}$ & $7.01 \pm 0.78 \mathrm{C}$ \\
$0.12 / 30 / 1.0$ & $97.9 \pm 0.5^{\mathrm{A}}$ & $185.42 \pm 6.15^{\mathrm{bc}}$ & $22.22 \pm 3.12 \mathrm{~B}$ \\
$0.04 / 50 / 1.0$ & $94.5 \pm 1.2^{\mathrm{CD}}$ & $214.40 \pm 8.15^{\mathrm{ab}}$ & $5.74 \pm 1.17 \mathrm{C}$ \\
$0.12 / 50 / 1.0$ & $95.3 \pm 0.8^{\mathrm{BCD}}$ & $238.69 \pm 6.48^{\mathrm{a}}$ & $20.03 \pm 0.42 \mathrm{~B}$ \\
$0.04 / 30 / 2.0$ & $97.7 \pm 0.8^{\mathrm{AB}}$ & $112.30 \pm 4.51^{\mathrm{d}}$ & $9.34 \pm 1.13 \mathrm{C}$ \\
$0.12 / 30 / 2.0$ & $97.9 \pm 0.3^{\mathrm{A}}$ & $122.95 \pm 5.77^{\mathrm{d}}$ & $30.57 \pm 4.36 \mathrm{~A}$ \\
$0.04 / 50 / 2.0$ & $93.8 \pm 0.9^{\mathrm{D}}$ & $148.30 \pm 3.26^{\mathrm{cd}}$ & $7.35 \pm 1.15 \mathrm{C}$ \\
$0.12 / 50 / 1.0$ & $93.4 \pm 0.7^{\mathrm{D}}$ & $175.33 \pm 10.55^{\mathrm{bc}}$ & $23.73 \pm 3.74 \mathrm{~B}$ \\
$0.08 / 40 / 1.5$ & $96.4 \pm 0.6^{\mathrm{ABC}}$ & $164.85 \pm 13.70^{\mathrm{c}}$ & $19.73 \pm 1.61 \mathrm{~B}$ \\
\hline
\end{tabular}

* The same letters in each column represent statistically equal values according to Tukey's test at the 5\% significance level.

* Experimental conditions: Transmembrane pressure (MPa) / temperature $\left({ }^{\circ} \mathrm{C}\right) /$ concentration $\left(\mathrm{g} \mathrm{kg}^{-1}\right)$.

According to Sulaiman [18], the linear and branched structure of the pectin molecule allows for mobility and deformation of the chain under the action of an external force, favoring its insertion into the membrane pores. As higher tension on the molecules greater force necessary to pass them, increasing obstruction of the pores and resistance to fouling. Additionally, the increase in transmembrane pressure has a compacting effect on the gel layer on the pectin surface, raising the filtering cake resistance.

The increase in the concentration leads to an increase in the fouling resistance, which was greater for the assays with the highest transmembrane pressure $(0.12 \mathrm{MPa})$. The fouling resistance found in assay $2\left(0.12 \mathrm{MPa}, 30{ }^{\circ} \mathrm{C}\right.$ and $\left.1.0 \mathrm{~g} \mathrm{~kg}^{-1}\right)$ was $(20.03 \pm 0.42) \times 1.0^{8} \mathrm{~m}^{2} \mathrm{~kg}^{-1}$, while that found in assay 6 $\left(0.12 \mathrm{MPa}, 30{ }^{\circ} \mathrm{C}\right.$ and $\left.2.0 \mathrm{~g} \mathrm{~kg}^{-1}\right)$ had a value of $(30.57 \pm 4.36)$ $\mathrm{x} 1.0^{8} \mathrm{~m}^{2} \mathrm{~kg}^{-1}$. The larger amount of pectin in the system leads to an accumulation of larger mass on the surface, favoring an increase in the filtration cake, which in this case was intensified by the compaction effect exerted by the pressure of $0.12 \mathrm{MPa}$.

\section{B. Behavior of Permeate Flux}

The behavior of the permeate flux initially had a sharp decay, followed by leveling. Fig. 2(a) and Fig. 2(b) display the permeate flux values observed in $1 \mathrm{~h}$ assays in continuous mode at $1.0 \mathrm{~g} \mathrm{~kg}^{-1}$ and $2.0 \mathrm{~g} \mathrm{~kg}^{-1}$, respectively. Assay $4(0.12$ $\mathrm{MPa}, 50{ }^{\circ} \mathrm{C}$ and $1.0 \mathrm{~g} \mathrm{~kg}^{-1}$ ) gave the highest flux after $1 \mathrm{~h}$ $\left(238.69 \pm 6.48 \mathrm{~kg} \mathrm{~m}^{-2} \mathrm{~h}^{-1}\right)$. 
TABLE II: Permeate Flux Data Modelling

\begin{tabular}{|c|c|c|c|c|c|c|c|c|c|c|}
\hline Models* & Parameters & 1 & 2 & 3 & 4 & 5 & 6 & 7 & 8 & 9 \\
\hline \multirow{3}{*}{$\begin{array}{c}\text { Complete } \\
\text { Blocking }(\mathrm{n}=2.0)\end{array}$} & $\mathrm{k}_{2.0}$ & 9.06 & 9.60 & 53.28 & 7.86 & 12.96 & 4.74 & 9.00 & 11.52 & 8.76 \\
\hline & $\mathrm{R}^{2}(\%)$ & 93.5 & 87.9 & 79.5 & 95.2 & 91.7 & 89.4 & 94.2 & 89.4 & 93.5 \\
\hline & SSR & 6550 & 14567 & 33745 & 12929 & 3207 & 14972 & 7449 & 12522 & 8105 \\
\hline \multirow{3}{*}{$\begin{array}{l}\text { Internal blocking } \\
\qquad(\mathrm{n}=1.5)\end{array}$} & $\mathrm{k}_{1.5} \times 10^{2}$ & 2.99 & 3.42 & 4.62 & 1.93 & 2.95 & 2.60 & 2.84 & 3.10 & 2.80 \\
\hline & $\mathrm{R}^{2}(\%)$ & 80.6 & 89.6 & 77.4 & 79.5 & 73.6 & 82.2 & 70.7 & 76.4 & 81.2 \\
\hline & SSR & 38736 & 94295 & 261222 & 90679 & 23563 & 46033 & 61573 & 69802 & 47170 \\
\hline \multirow{2}{*}{$\begin{array}{l}\text { Partial Blocking } \\
\qquad(\mathrm{n}=1)\end{array}$} & $\mathrm{R}^{2}(\%)$ & 95.0 & 90.4 & 84.7 & 96.4 & 93.4 & 90.6 & 95.5 & 91.4 & 95.0 \\
\hline & SSR & 4876 & 11378 & 104524 & 9521 & 2562 & 11381 & 5509 & 9966 & 6062 \\
\hline \multirow{3}{*}{$\begin{array}{l}\text { Cake filtration } \\
\qquad(\mathrm{n}=0)\end{array}$} & $\mathrm{k}_{0} \times 10^{4}$ & 1.56 & 1.06 & 2.21 & 0.65 & 4.34 & 1.70 & 2.24 & 1.30 & 1.51 \\
\hline & $\mathrm{R}^{2}(\%)$ & 96.4 & 94.3 & 96.3 & 97.4 & 95.1 & 91.6 & 96.9 & 93.0 & 96.4 \\
\hline & SSR & 4624 & 6251 & 8285 & 7364 & 2027 & 8132 & 3359 & 11417 & 4192 \\
\hline \multirow{3}{*}{$\begin{array}{c}\text { Classic filtration } \\
\text { model }\end{array}$} & $\times 10^{5}$ & 0.252 & 0.456 & 8.40 & 0.354 & 6.31 & 0.329 & 0.130 & 0.570 & 0.245 \\
\hline & $\mathrm{R}^{2}(\%)$ & 80.5 & 89.0 & 66.6 & 81.3 & 70.0 & 82.3 & 70.2 & 80.6 & 80.7 \\
\hline & SSR & 5802 & 5970 & 39096 & 15775 & 10336 & 57532 & 16828 & 40385 & 7273 \\
\hline
\end{tabular}
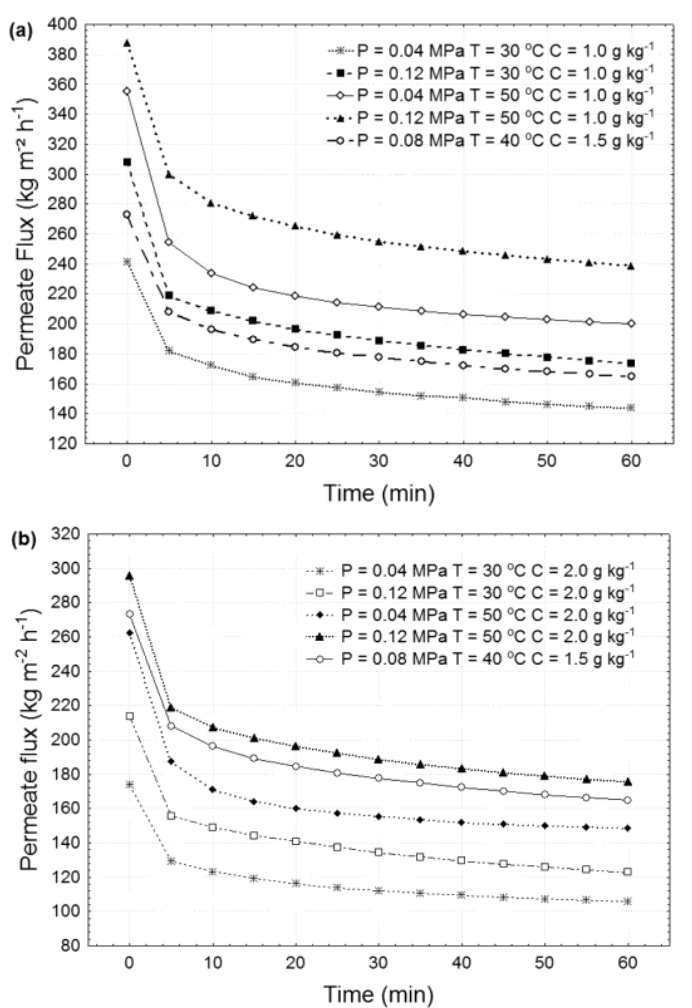

Fig. 2. Permeate flux behavior: (a) $\mathrm{C}=1.0 \mathrm{~g} \mathrm{~kg}^{-1}$, (b) $\mathrm{C}=2.0 \mathrm{~g} \mathrm{~kg}^{-1}$.

To identify the mechanism of fouling during pectin microfiltration, it was adopted the comparative study between experimental values of permeate flux and different mathematical models for restrictive flux, like other studies [23], [24]. The coefficient of determination $\left(\mathrm{R}^{2}\right)$ and the sum of the square of residuals (SSR) between numerical predictions and experimental data were the criterion used to choice the best fit model for each assay evaluated.

For all assays the cake filtration model $(n=0)$ derived of the pore blocking model showed the best fitting. The cake filtration model had SSR values between 2,020 and 11,500 and the best $\mathrm{R}^{2}$ observed, as showed in Table II, while the other models had high values of SSR between 2,500 and 262,000 and, therefore, they do not describe the pectin-membrane interaction phenomena. For all models considered in this study, independent of the operational conditions, the precision in the fitted results at the beginning is poor due these models evaluated only the fouling aspects, and the initial of the process the resistive mechanisms are not fully formed, specially the dynamic resistances, like the polarized layer.

The classical filtration model has significant deviations (see Table II) due its restrictions. This model does not estimate the initial flux value and does not take into account the effect of surface renewal promoted by the cross-flow flux. Fig. 3 presents the experimental flux values and the values estimated by all models used for the maximum flux observed in total recycling mode $\left(0.12 \mathrm{MPa}, 50{ }^{\circ} \mathrm{C}\right.$ and $\left.1.0 \mathrm{~g} \mathrm{~kg}^{-1}\right)$.

Assays in the total recycling mode, or in process with lower values of concentrate factor, the blocking model can be successful to describe the fouling phenomena, despite the deviations observed in the initial region due the limitation of the pore blockage models in estimating the initial decay (Fig. 3). However, they predict the behavior in the region where the fouling effects predominate. In contrast, the classical filtration model is not able to describe the balance relationship between the renewal effect and the interactions due the surface accumulation and the polarization layer, which justifies the high deviations in the initial and final moments of the process.

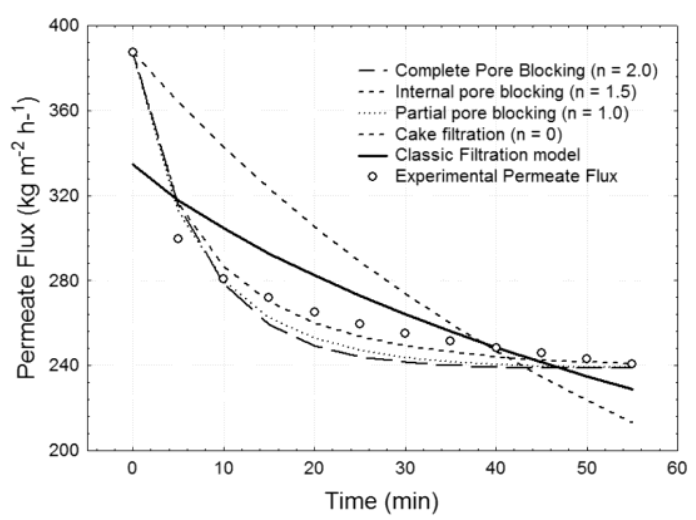

Fig. 3. Fitting of the pore blockage and the classical filtration models $(\mathrm{C}=$ $1.0 \mathrm{~g} \mathrm{~kg}^{-1}, \mathrm{~T}=50{ }^{\circ} \mathrm{C}$ and $\mathrm{P}=0.12 \mathrm{MPa}$ ).

Based on the fitting described for these models, was observed that the fouling profile suggests a surface 
interaction between the pectin and the pore caused by the pore opening sealing due the deposition of pectin on surface in the form of gel, as proposed by Rai [25]. This restrictive phenomenon was expected, because pectin is a long macromolecule and also because of characteristics interactions between the molecules, which results gelling properties to pectin in the presence of sugars. The formation of gel on the surface is presumed, due the high pectin aggregation capacity (see Fig. 1), which allows the retention of pectin in the membranes of the microfiltration process.

Barros [23] observed the predominant blocking mechanism by cake filtration in ultrafiltration of pineapple juice (with large amount of pectin, between $1 \%$ at $3 \%$ ), especially after the first minutes of operation, due the high interaction between the colloidal materials and membrane surface. According with Jiraratananon [26], glycoside molecules have the tendency to form aggregates with other macromolecules by hydrogen bounding, and form cake on the surface. In this case, the convective flux, direct form the bulk solution toward the membrane, prevails on the rate of back diffusion of colloidal materials reject by surface membrane.

\section{CONCLUSION}

This study evidenced the potential application of crossflow microfiltration processes to the treatment of pectin with rejection coefficients of up to $97.8 \%$.

The highest steady-state permeate flux obtained was $238.69 \mathrm{~kg} \mathrm{~m}^{-2} \mathrm{~h}^{-1}$ at $0.12 \mathrm{MPa}, 50{ }^{\circ} \mathrm{C}$ and $1.0 \mathrm{~g} \mathrm{~L}^{-1}$, while the greatest fouling resistance observed was the order of $30.57 \times$ $10^{8} \mathrm{~m}^{2} \mathrm{~kg}^{-1}$ for experimental conditions of $0.12 \mathrm{MPa}, 30{ }^{\circ} \mathrm{C}$ and $2.0 \mathrm{~g} \mathrm{~kg}^{-1}$.

From the analysis of the blocking models, we conclude that the dominant restriction mechanisms are the surface effects, notably the filtration cake due the formation of gel layer on the membrane surface.

\section{ACKNOWLEDGMENT}

The authors are grateful for the scholarship provided by CAPES, the research grant and support of the Graduation Program of Food Engineering (Federal University of Paraná, Curitiba, Brazil) and the pectin supplied by CP Kelco S.A.

\section{REFERENCES}

[1] G. A. Morris, T. J. Foster, and S. E. Harding, "The effect of the degree of esterification on the hydrodynamics properties of citrus pectin," Food Hydrocolloid., vol. 14, pp. 227-235, May, 2000.

[2] U. Kalapathy and A. Proctor, "Effect of acid extraction and alcohol precipitation conditions on the yield and purity of soy hull pectin," Food Chem., vol. 73, pp. 393-396, June, 2001.

[3] S. Wang, F. Chen, J. Wu, Z. Wang, X. Liao, and X. Hu, "Optimization of pectin extraction assisted by microwave from apple pomace using response surface methodology," J. Food Eng., vol. 78, pp. 393-396, January, 2007.

[4] D. D. Joye and G. A Luzio, "Process for selective extraction of pectins from plant material by differential pH," Carbohyd. Polym., vol. 43, pp 337-342, December, 2000.

[5] B. M. Yapo, B. Whatelet, and M. Paquot, "Comparison of alcohol precipitation and membrane filtration effects on sugar beet pulp pectin chemical features and surface properties," Food Hydrocolloid., vol. 21, pp. 245-255, March, 2007.

[6] D. Hantziantoniou and J. A. Howell, "Influence of the properties and characteristics of sugar-beet pulp extract on its fouling and rejection behavior during membrane filtration," Desalination, vol. 148, pp. 67-72, September, 2002.

[7] K. F. M. Yunos and R. W. Field, "Effect of sandwich configuration of ultrafiltration membranes on protein fractionation," Desalination, vol 199, pp. 222-224, November, 2006.

[8] P. Sarkar, S. Ghosh, S. Dutta, D. Sen, and C. Bhattacharjee, "Effect of different operating parameters on the recovery of proteins from casein whey using a rotating disc membrane ultrafiltration cell," Desalination, vol. 249, pp. 5-11, November, 2009.

[9] M. Moresi and I. Sebastiani, "Pectin recovery from model solutions using a laboratory-scale ceramic tubular UF membrane module," $J$. Membrane Sci., vol. 322, pp. 349-359, September, 2008.

[10] C. W. Cho, D. Y. Lee, and C. W. Kim, "Concentration and purification of soluble pectin from mandarin peels using crossflow microfiltration," Carboh. Polym., vol. 54, pp. 21-26, October, 2003.

[11] R. Jiraratananon and A. Chanachai, "Study of fouling in the ultrafiltration of passion fruit juice," J. Membrane Sci., vol. 111, pp. 39-48, March, 1996.

[12] K. Riedl, B. Girard, and R. B. Lencki, "Interactions responsible for fouling layer formation during apple juice microfiltration," J. Agri. Food Chem., vol. 46, pp. 2458-2464, July, 1998.

[13] J. Yu and R. W. Lencki, "Effect of enzyme treatments on the fouling behavior of apple juice during microfiltration," J. Food Eng., vol. 63, pp. 413-423, August, 2004

[14] A. B. Koltuniewicz, R. W. Field, and T. C. Arnot, "Crossflow and dead-end microfiltration of oily-water emulsion. Part I: experimental study and analysis of the flux decline," J. Membrane Sci., vol. 102, pp. 193-207, June, 1995.

[15] A. Drews, "Membrane fouling in membrane bioreactors Characterization, contradictions, cause and cures," J. Membrane Sci., vol. 363, pp. 1-22, November, 2010.

[16] V. R. Silva and A. P. Scheer, "Study of aqueous pectin solution microfiltration process by ceramic membrane," Acta Sci. Technol., vol. 33, pp. 215-220, April, 2011.

[17] V. R. Silva, F. Hamerski, and A. P. Scheer, "Pretreatment of aqueous pectin solution by cross-flow microfiltration: Analysis of operational parameters, degree of concentration and pectin losses," Int. J. Food Sci. Technol., vol. 47, pp. 1246-1252, June, 2012.

[18] M. Z. Sulaiman, N. M. Sulaiman, and M. Shamel, "Ultrafiltration studies on solutions of pectin, glucose and their mixtures in a pilot scale crossflow membrane unit," Chem. Eng. J., vol. 84, pp. 557-563, December, 2001.

[19] S. A. M. Mourouzis and A. J. Karabelas, "Whey protein fouling of microfiltration ceramic membranes - Pressure effects," J. Membrane Sci. vol. 282, pp. 124-132, October, 2006.

[20] B. J. Wang, T. C. Wei, and Z. R. Yu, "Effect of operating temperature on component distribution of West Indian cherry juice in a microfiltration system," $L W T$ - Food Sci. Technol., vol. 38, pp. 683-689, September, 2005.

[21] J. Hérmia, "Constant pressure blocking filtration laws, Applications to power-law non-Newtonian fluids," Trans. Ichem. E., vol. 60, pp. 183-187, 1982.

[22] R. W. Field, D. Wu, J. A. Howell, and B. B. Gupta, "Critical flux concept for microfiltration fouling," J. Membrane Sci. , vol. 100, pp. 259-272, April, 1995.

[23] S. T. D. Barros, C. M. G. Andrade, E. S. Mendes, and L. Peres, "Study of fouling mechanism in pineapple juice clarification by ultrafiltration," J. Membrane Sci., vol. 215, pp. 213-224, April, 2003.

[24] M. C. Vicent-Vela, S. Álvarez-Blanco, J. Lora-García, and E. B. Rodríguez, "Analysis of membrane pore blocking models adapted to crossflow ultrafiltration in the ultrafiltration of PEG," Chem. Eng. J., vol. 149, pp. 232-241, July, 2009.

[25] P. Rai, G. C. Majumdar, S. Dasgupta, and S. De, "Understanding ultrafiltration performance with mosambi juice in an unstirred batch cell," J. Food Process Eng., Vol. 28, pp. 166-180, April, 2005.

[26] R. Jiraratananon, D. Uttapap, and C. Tangamornsuksun, "Self-forming dynamic membrane for ultrafiltration of pineapple juice," J. Membrane Sci., vol. 129, pp. 135-143, June, 1997.

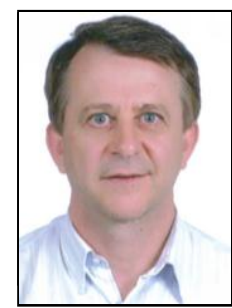

Marcelino Luiz Gimenes graduated in chemical engineering in 1981 from State University of Maringá, and received M. Eng. from State University of Campinas. He obtained a PhD degree in chemical engineering from Leeds University in England in 1992, and since 1986 he has been working as a lecturer at State University of Maringá, Brazil.

His main research areas are separation processes including adsorption and membrane separation 
technologies. He has supervisioned MSc and $\mathrm{PhD}$ students and published several papers in International journals, National journals and International conferences.

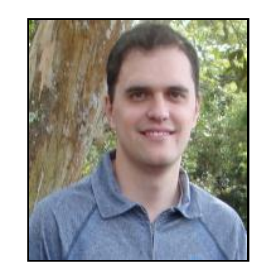

Vitor Renan da Silva graduated in chemical engineering in 2006 from Federal University of Paraná. He obtained a master degree in food technology from Federal University of Paraná in Brazil in 2009, and since 2011 he has been working as an engineer at environmental department of Curitiba, Brazil. His main research areas are separation processes including adsorption, ultrafiltration and microfiltration.

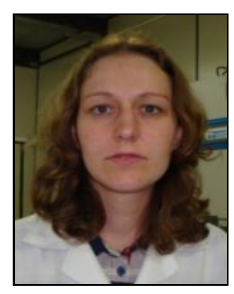

Fabiane Hamerski graduated in food chemistry (2006), who obtained her master degree in food technology from Federal University of Paraná (2009), is a doctoral student in Food Engineering in the same university. Her current research area is the esterification of fatty acids to obtain emulsifier products, and she has experience in analytical chemistry, including chromatography (HPLC and CG).

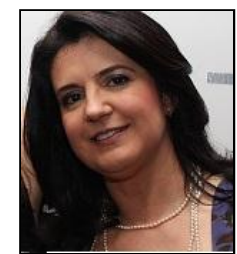

Agnes de Paula Scheer received her bachelor's at chemical engineering from Federal University of Paraná (1980), master's at science and technology of food from Federal University of Paraná (1991) and doctorate at chemical engineering from State University of Campinas (2002). She was an associate professor since 1988 at Chemical Engineering Department and has supervised Master and $\mathrm{PhD}$ students. She has experience in chemical engineering, focusing on operations of separation, acting on the following subjects: adsorption, emulsions, membrane separation and rheology. Published several papers in International journals, National journals and in annals of events.. 